\title{
ANALISIS VALUE ENGINEERING PADA STRUKTUR BANGUNAN DENGAN METODE ANALYTICAL HIERARCHY PROCESS (AHP) (STUDI KASUS: PROYEK SUPPORTING UNIT DPRD KOTA SALATIGA)
}

\author{
Sukmawati Santika Arina Musliha ${ }^{1)}$, Fajar Sri Handayani ${ }^{2}$, Muji Rifai ${ }^{3)}$ \\ 1)Mahasiswa Fakultas Teknik, Program Studi Teknik Sipil, Universitas Sebelas Maret \\ 2), 3)Pengajar Fakultas Teknik, Program Studi Teknik Sipil, Universitas Sebelas Maret \\ Jl. Ir. Sutami 36A, Kentingan Surakarta 57126; Telp. (0271) 634524, Fax 662118 \\ Email: sukmawatisantikaarinamusliha@student.uns.ac.id
}

\begin{abstract}
In a job segment that has a large value, it can be identified to make savings without reducing its quality, or it is often called Value Engineering. In this construction, structural works cost $32 \%$ of the total project cost. The consideration behind this research was the structural design of the building which was considered to have large dimensions and can be efficient. The purpose of this study was to identify, which jobs were analyzed, chosen the best alternative, and calculated the cost comparison before and after the analysis. At the analysis stage, the AHP method was used with the help of expert choice software. The data used consisted of questionnaires from several experts, $\mathrm{RAB}$, shop drawings, work unit price lists, technical specifications, and applicable regulations. With cost breakdown, three strategic work items were obtained to be analyzed, namely plate, beam, and column work. The structural design recalculated with the respondent's consideration and came up with an alternative precast. From the analysis carried out, the chosen alternative was not different from the initial structure type, namely precast plate with conventional columns and beams with dimensional changes. The savings obtained were IDR $231,708,894.36$ or $2.55 \%$ of the total project cost.
\end{abstract}

Keywords: AHP, Expert Choice, Precast, Structure, V alue Engineering

\begin{abstract}
Abstrak
Pada segmen pekerjaan yang memiliki nilai besar dapat dilakukan identifikasi untuk dilakukan penghematan tanpa mengurangi kualitasnya atau sering disebut V alue Engineering. Pada pembangunan ini, pekerjaan struktur memakan biaya sebesar 32\% dari keseluruhan biaya proyek. Pertimbangan yang melatarbelakangi penelitian ini adalah desain struktur gedung yang dinilai memiliki dimensi yang besar dan dapat diefisienkan. Tujuan dari penelitian ini adalah untuk mengidentifkasi pekerjaan mana yang dapat dianalisis, memilih alternatif terbaik, dan menghitung perbandingan biaya sebelum dengan setelah dianalisis. Pada tahap analisa digunakan metode Analytical Hierarchy Process (AHP) dengan bantuan software expert choice. Data yang digunakan terdiri dari kuisioner dari beberapa expert, Rencana Anggaran Biaya (RAB), shop drawing, daftar harga satuan pekerjaan, spesifikasi teknis, dan peraturan-peraturan yang berlaku Dengan cost breakdown didapat tiga item pekerjaan yang strategis untuk dianalisis yaitu pekerjaan pelat, balok, dan kolom. Dilakukan perhitungan ulang desain struktur dengan pertimbangan responden dan memunculkan alternatif precast. Dari analisis yang dilakukan, alternatif yang terpilih tidak berbeda dengan tipe struktur awal yaitu pelat precast dengan kolom dan balok konvensional dengan dilakukan perubahan dimensi. Penghematan yang didapatkan sebesar Rp 231.708.894,36 atau sebesar 2,55 \% dari keseluruhan biaya proyek.
\end{abstract}

Kata Kunci : AHP, Expert Choice, Precast, Struktur, Value Engineering

\section{PENDAHULUAN}

Pembangunan infrastuktur menjadi salah satu indikator perkembangan suatu negara. Di Indonesia sendiri dunia konstruksi berkembang pesat sejalan dengan pertumbuhan pasar properti, peningkatan investasi swasta, dan pertumbuhan anggaran pemerintah. Kualitas infrastruktur mencermikan sumber daya negara suatu negara, kualitas infrastruktur yang berkualitas dihasilkan oleh sumber daya manusia yang andal dan kompetitif. Agar para pelaku usaha dapat bertahan dan bersaing, diperlukan perencanaan yang matang dan pengelolaan yang baik sehingga didapatkan hasil yang optimal dan efisien.

Rekayasa nilai / Value Engineering (VE) dikembangkan pada tahun 1940-an oleh Lawrence D. Miles, untuk mengatasi masalah kekurangan bahan penting untuk produk yang akan diproduksi selama perang dunia kedua. Di Indonesia, Value Engineering (VE) telah diimplementasikan sejak tahun 1986 pada pembangunan Flyover Cawang. Menurut peraturan Dinas Pekerjaan Umum Nomor 222/KPTS/CK/1991 Direktorat Jendral Cipta Karya, bangunan dengan nilai konrak lebih dari 1 milyar harus menjalani proses analisis Value Engineering (VE). 
Jurnal Matriks Teknik Sipil

DOI: https://dx.doi.org/10.20961/mateksi.v9i1.51241

ISSN: 2354-8630

E-ISSN: 2723-4223

Vol 9, No 1 (2021): Maret

Studi kasus pada penelitian Value Engineering (VE) ini adalah pada Proyek Pembangunan Supporting Unit DPRD Kota Salatiga. Bangunan yang terletak di Jl. Sukowati No.51 Salatiga ini terdiri dari 4 lantai. Pada pembangunan ini, pekerjaan struktur memakan biaya sebesar 32\% dari keseluruhan biaya proyek. Pertimbangan yang melatar belakangi penelitian ini adalah desain struktur gedung yang dinilai memiliki dimensi yang besar dan dapat di efisienkan. Dengan pertimbangan tersebut, diharapkan dengan diadakannya penelitian ini akan diperoleh alternatif yang efisien dan optimal sehingga didapat penghematan biaya.

\section{DASAR TEORI}

Menurut Dell'Isola (1974), Rekayasa Nilai adalah suatu pendekatan sistematis untuk memperoleh hasil yang maksimal dari setiap biaya yang dikeluarkan. Dimana diperlukan suatu usaha kreatif untuk menganalisis fungsi dengan menghapus atau memodifikasi penambahan harga yang tidak perlu dalam proses pembiayaan konstruksi, operasi atau pelaksanaan, pemeliharaan, penggantian alat dan lain-lain.

Cost breakdown adalah suatu analisis yang digunakan untuk menggambarkan distribusi biaya setiap item pekerjaan dalam suatu proyek. Cost model adalah suatu model yang digunakan untuk menggambarkan distribusi/alokasi biaya suatu proyek. Analisis fungsi merupakan suatu pendekatan untuk memperoleh suatu nilai tertentu, dalam hal ini fungsi adalah karakteristik/keistimewaan dari suatu produk atau proyek yang membuat suatu produk atau proyek dapat berfungsi atau dijual.

Metode AHP dikembangkan oleh Thomas L. Saaty. Menurut Saaty (1993), struktur hierarki diartikan sebagai representasi dari suatu masalah yang kompleks dalam suatu struktur multi level dimana level pertama adalah tujuan, yang diikuti level faktor, kriteria, sub kriteria, dan seterusnya ke bawah hingga level terakhir dari alternatif. Melalui struktur hierarki, suatu masalah yang kompleks dapat diuraikan ke dalam beberapa kelompok yang kemudian kelompok-kelompok tersebut disusun dalam struktur hierarki agar permasalahan menjadi lebih terstruktur dan sistematis.

Expert Choice merupakan suatu program aplikasi yang mendukung collaborative decision. Aplikasi ini digunakan sebagai salah satu alat dalam menentukan keputusan. Proses komputasi pada Expert Choice didasarkan pada Analytical Hierarchy Process (AHP).

Beton adalah campuran Semen Portland atau semen hidrolisis lainnya, agregat halus, agregat kasar, dan air, dengan atau tanpa bahan campuran tambahan (admixture). Beton bertulang adalah beton struktural yang ditulangi dengan tidak kurang dari jumlah baja prategang atau tulangan nonprategang yang ditetapkan dalam standar. Beton pracetak adalah elemen struktur beton yang dicetak di tempat lain dari posisi akhirnya dalam struktur. Pada dasarnya, sistem ini melakukan pengecoran komponen di tempat khusus (fabrikasi), lalu dibawa ke lokasi (transportasi) untuk disusun menjadi struktur yang utuh (ereksi). (SNI 2847:2019)

\section{METODE PENELITIAN}

Teknik pengumpulan data yang dipakai dalam penelitian ini yaitu penyebaran kuesioner, studi dokumen, dan studi pustaka. Kuesioner diberikan kepada kontraktor, konsultan, regulator (Dinas PU) dan akademisi yang expert pada penelitian ini. Studi dokumen dilakukan dengan mengkaji dokumen yang merupakan data sekunder dalam penelitian. Studi pustaka digunakan untuk mencari data dan informasi yang paling sesuai mengenai landasan teori yang bersumber pada referensi yang relevan dengan topik penelitian.

Metode analisis data yang digunakan adalah melakukan pendekatan sistematik dan terorganisir dengan Value Engineering Job Plan. Analisis V alue Engineering dilakukan lima tahap, yaitu:

1. Tahap Informasi, yaitu mengumpulkan sebanyak mungkin data mengenai proyek. Tahap ini bertujuan untuk memperoleh permasalahan dari proyek yang akan di analisis dan mengetahui item pekerjaan yang strategis untuk dilakukan analisa;

2. Tahap Pengembangan Ide Spekulatif, yaitu mengembangkan sebanyak mungkin alternatif yang bisa memenuhi fungsi primer atau pokoknya;

3. Tahap Analisis, yaitu mengusulkan alternatif dan memertimbangkan keuntungan dan kerugiannya dari berbagai sudut, kemudian menggunakan metode AHP untuk membuat ranking hasil evaluasi; 
Jurnal Matriks Teknik Sipil

DOI: https://dx.doi.org/10.20961/mateksi.v9i1.51241

ISSN: 2354-8630

E-ISSN: 2723-4223

Vol 8, No 4 (2021): Maret

4. Tahap Pengembangan, yaitu menyiapkan semua ide atau pendapat secara keseluruhan untuk diteliti ke dalam desain awal (preliminary), dibuatkan gambaran solusi, diestimasi efisiensi yang didapatkan dari desain asal dan dengan desain yang baru diusulkan;

5. Tahap Rekomendasi, berupa penyampaian hasil analisis kepada pihak pengambil keputusan (Regulator).

\section{HASIL DAN PEMBAHASAN}

Tahap Informasi

Pada tahap ini dilakukan pengumpulan data sebanyak mungkin mengenai proyek, yang bertujuan untuk memperoleh permasalahan dari proyek yang dianalisis dan mengetahui item pekerjaan yang strategis untuk dilakukan analisa.

Proyek ini merupakan gedung 4 lantai yang berfungsi sebagai supporting unit, dengan struktur beton bertulang dan precast, yang menghabiskan biaya sebesar Rp. 9.082.391.093,31. Dari biaya ini dibuat dalam cost model seperti dibawah ini untuk mengetahui biaya untuk masing-masing pekerjaan.

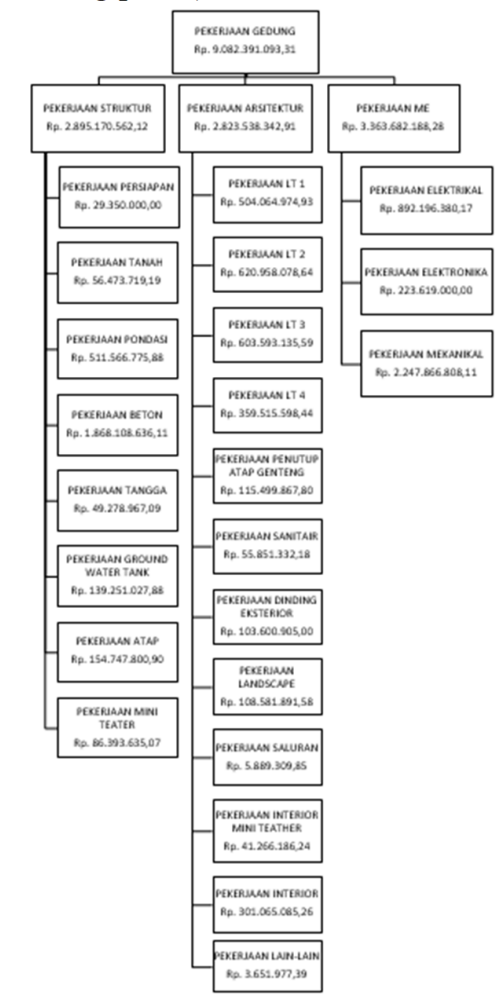

Gambar 1. Cost Model proyek tinjauan

Dari bagan diatas dapat dilihat bahwa item pekerjaan beton memiliki anggaran biaya terbesar kedua dibanding pekerjaan lain. Kemudian dibuat cost breakdown dari pekerjaan beton. Dari tabel dibawah diambil tiga pekerjaan berbiaya terbesar yang akan dianalisis yaitu pekerjaan pelat, balok, dan kolom.

Tabel 1. Cost Breakdown pekerjaan beton

\begin{tabular}{cll}
\hline Item & Pekerjaan & Biaya \\
\hline 1 & Pekerjaan Sloof & Rp. 143.659.461,11 \\
2 & Pekerjaan Kolom & Rp. 438.858.133,02 \\
3 & Pekerjaan Balok & Rp. 408.732.541,21 \\
3 & Pekerjaan Balok Ring & Rp. 86.995.836,44 \\
5 & Pekerjaan Pelat & Rp. 622.465.395,24 \\
6 & Pekerjaan Beton Dinding Lift & Rp. 167.397.269,09 \\
\hline & Total & Rp. 1.868.108.636,11 \\
\hline & Biaya proyek keseluruhan & Rp. 9.082.391.093,31 \\
\hline
\end{tabular}


Untuk memperoleh data parameter kualitatif, dilakukan diskusi dengan para ahli melalui kuesioner. Kuesioner diberikan kepada 8 responden yang expert di bidangnya yang terdiri dari kontraktor, konsultan, akademisi, dan regulator (Dinas PU). Responden ini dipilih karena mengerti, merasakan, dan memiliki kepentingan terhadap permasalahan ini. Kuesioner terdiri dari 25 pertanyaan yang berupa matriks perbandingan berpasangan yang mempresentasikan kepentingan relatif elemen terhadap elemen lainnya.

\section{Tahap Pengembangan Ide Spekulatif}

Pada tahap ini dilakukan pengembangan sebanyak mungkin alternatif. Alternatif ditinjau dari segi dimensi/desain, biaya, dan waktu penyelesaian.

Dari data desain existing, dilakukan perhitungan ulang dan diskusi dengan responden sehingga didapat alternatif dimensi yang baru tanpa mengabaikan faktor keamanan. Desain dimensi yang baru ini dibuat dua laternatif pelaksanaan yaitu dengan metode konvensional dan precast. Kemudian dilanjutkan perhitungan biaya dan waktu yang diperlukan untuk masing-masing alternatif pekerjaan.

Tabel 2. Hasil analisis desain struktur pelat

\begin{tabular}{|c|c|c|c|c|c|c|}
\hline \multirow{2}{*}{ Nama } & \multicolumn{3}{|c|}{ Desain Existing } & \multicolumn{3}{|c|}{ Desain Baru } \\
\hline & Tebal & & ggan & Tebal & & angan \\
\hline \multirow{2}{*}{ Lt 2} & \multirow{2}{*}{$12(\mathrm{~cm})$} & Arah X & $\varnothing 12-200$ & \multirow{2}{*}{$10(\mathrm{~cm})$} & Arah X & $\varnothing 12-200$ \\
\hline & & Arah Y & $\varnothing 12-200$ & & Arah Y & $\varnothing 12-200$ \\
\hline \multirow{2}{*}{ Lt 3} & \multirow{2}{*}{$12(\mathrm{~cm})$} & Arah X & Ø 12-200 & \multirow{2}{*}{$10(\mathrm{~cm})$} & Arah X & Ø $12-200$ \\
\hline & & Arah Y & $\varnothing 12-200$ & & Arah Y & Ø 12-200 \\
\hline \multirow{2}{*}{ Lt 4} & \multirow{2}{*}{$12(\mathrm{~cm})$} & Arah X & Ø 12-200 & \multirow{2}{*}{$10(\mathrm{~cm})$} & Arah X & Ø $12-200$ \\
\hline & & Arah Y & $\varnothing 12-200$ & & Arah Y & $\varnothing 12-200$ \\
\hline \multirow{2}{*}{ Pelat dak atap } & \multirow{2}{*}{$12(\mathrm{~cm})$} & Arah X & $\varnothing 12-200$ & \multirow{2}{*}{$10(\mathrm{~cm})$} & Arah X & Ø 12-200 \\
\hline & & Arah Y & $\varnothing 12-200$ & & Arah Y & $\varnothing 12-200$ \\
\hline
\end{tabular}

Dari perhitungan ulang untuk struktur pelat, diperoleh tebal desain baru yaitu sebesar $10 \mathrm{~cm}$ dari tebal sebelumnya sebesar $12 \mathrm{~cm}$ dengan jumlah tulangan dan jarak antar tulangan yang sama.

Tabel 3. Hasil analisis desain struktur balok

\begin{tabular}{|c|c|c|c|c|c|c|c|c|c|c|}
\hline \multirow[b]{2}{*}{ Nama } & \multicolumn{5}{|c|}{ Desain Existing } & \multicolumn{5}{|c|}{ Desain Baru } \\
\hline & Dimensi & Tumpuan & $\begin{array}{l}\text { Tumpuan } \\
\text { Extra }\end{array}$ & $\begin{array}{l}\text { Lapan- } \\
\text { gan }\end{array}$ & $\begin{array}{l}\text { Lapan- } \\
\text { gan } E_{X-} \\
\text { tra }\end{array}$ & Dimensi & Tumpuan & $\begin{array}{l}\text { Tumpuan } \\
\text { Extra }\end{array}$ & Lapangan & $\begin{array}{l}\text { Lapan- } \\
\text { gan } E_{X}- \\
\text { tra }\end{array}$ \\
\hline \multirow{4}{*}{ LT 2} & $15 \times 25$ & 6D13 & & 6D13 & & $15 \times 25$ & 6D13 & & 6D13 & \\
\hline & $20 \times 30$ & 8D16 & & 8D16 & & $20 \times 30$ & 8D13 & & 8D13 & \\
\hline & $25 \times 50$ & $12 \mathrm{D} 16$ & 2D12 & $12 \mathrm{D} 16$ & 2D12 & $25 \times 47,5$ & $12 \mathrm{D} 16$ & 2D12 & $12 \mathrm{D} 16$ & 2D12 \\
\hline & $42,5 \times 25$ & 16D16 & 2D12 & $18 \mathrm{D} 16$ & 2D12 & $25 \times 42,5$ & 10D16 & 2D12 & 10D16 & 2D12 \\
\hline \multirow{5}{*}{ LT 3} & $15 \times 25$ & 6D13 & & 6D13 & & $15 \times 25$ & 6D13 & & 6D13 & \\
\hline & $20 \times 30$ & 8D16 & & 8D16 & & $20 \times 30$ & 8D13 & & 8D13 & \\
\hline & $25 \times 50$ & $12 \mathrm{D} 16$ & 2D12 & $12 \mathrm{D} 16$ & 2D12 & $25 \times 47,5$ & $12 \mathrm{D} 16$ & 2D12 & $12 \mathrm{D} 16$ & 2D12 \\
\hline & $42,5 \times 25$ & $12 \mathrm{D} 16$ & 2D12 & 18D16 & 2D12 & $25 \times 42,5$ & 10D16 & 2D12 & 10D16 & 2D12 \\
\hline & $30 \times 60$ & 12D19 & 2D12 & 12D19 & 2D12 & $30 \times 60$ & 12D19 & 2D12 & $12 \mathrm{D} 19$ & 2D12 \\
\hline \multirow{5}{*}{ LT 4} & $15 \times 25$ & 6D13 & & 6D13 & & $15 \times 25$ & 6D13 & & 6D13 & \\
\hline & $20 \times 30$ & 8D16 & & 8D16 & & $20 \times 30$ & 8D13 & & 8D13 & \\
\hline & $25 \times 50$ & $12 \mathrm{D} 16$ & 2D12 & $12 \mathrm{D} 16$ & 2D12 & $25 \times 47,5$ & $12 \mathrm{D} 16$ & 2D12 & $12 \mathrm{D} 16$ & 2D12 \\
\hline & $42,5 \times 25$ & 16D16 & 2D12 & $16 \mathrm{D} 16$ & 2D12 & $25 \times 42,5$ & 10D16 & 2D12 & 10D16 & 2D12 \\
\hline & $25 \times 68$ & 12D16 & 2D12 & $12 \mathrm{D} 14$ & 2D12 & $25 \times 65$ & $12 \mathrm{D} 16$ & 2D12 & $12 \mathrm{D} 16$ & 2D12 \\
\hline
\end{tabular}

Untuk desain struktur balok ada beberapa dimensi, jumlah tulangan, dan diameter tulangan yang berubah dari desain existing agar lebih efisien namun tetap aman. 
Tabel 4. Hasil analisis desain struktur kolom

\begin{tabular}{|c|c|c|c|c|c|}
\hline & \multirow{2}{*}{ Nama } & \multicolumn{2}{|c|}{ Dimensi Existing } & \multicolumn{2}{|c|}{ Dimensi Baru } \\
\hline & & Dimensi & Tulangan & Dimensi & Tulangan \\
\hline \multirow{3}{*}{ LT 1} & K1 & $30 \times 30$ & $12 \mathrm{D} 19^{\circ}$ & $30 \times 30$ & $12 \mathrm{D} 19$ \\
\hline & $\mathrm{K} 2$ & $20 \times 40$ & 8D19 & $20 \times 40$ & 8D19 \\
\hline & KP & $15 \times 15$ & 4D12 & $12,5 \times 12,5$ & 4D12 \\
\hline \multirow{4}{*}{ LT 2} & K1 & $30 \times 30$ & 12D19 & $30 \times 30$ & 12D19 \\
\hline & $\mathrm{K} 2$ & $20 \times 40$ & 8D19 & $20 \times 40$ & 8D19 \\
\hline & K3 & $15 \times 30$ & 6D13 & $15 \times 30$ & 6D13 \\
\hline & $\mathrm{KP}$ & $15 \times 15$ & $4 \mathrm{D} 12$ & $12,5 \times 12,5$ & 4D12 \\
\hline \multirow{4}{*}{ LT 3} & K1 & $30 \times 30$ & $12 \mathrm{D} 13$ & $30 \times 30$ & 12D13 \\
\hline & K2 & $20 \times 40$ & 8D13 & $20 \times 40$ & 8D13 \\
\hline & $\mathrm{K} 3$ & $15 \times 30$ & 6D13 & $15 \times 30$ & 6D13 \\
\hline & KP & $15 \times 15$ & $4 \mathrm{D} 12$ & $12,5 \times 12,5$ & 4D12 \\
\hline \multirow{4}{*}{ LT 4} & K1 & $30 \times 30$ & 12D19 & $30 \times 30$ & 12D13 \\
\hline & $\mathrm{K} 2$ & $20 \times 40$ & 8D19 & $20 \times 40$ & 8D13 \\
\hline & $\mathrm{K} 3$ & $15 \times 30$ & 6D13 & $15 \times 30$ & 6D13 \\
\hline & KP & $15 \times 15$ & 4D12 & $12,5 \times 12,5$ & 4D12 \\
\hline LT ATAP & K1 & $30 \times 30$ & 12D19 & $30 \times 30$ & 12D13 \\
\hline
\end{tabular}

Setelah dilakukan perhitungan ulang untuk desain kolom, tidak ada perubahan yang terlalu signifikan. Hanya ada perubahan dimensi dan diameter tulangan untuk 1 jenis kolom.

Tabel 5. Hasil perhitungan analisis biaya dan waktu

\begin{tabular}{lll}
\hline Alternatif & Biaya & Waktu \\
\hline Pelat half precast (existing) & Rp 622.465.395,24 & 14 hari \\
Pelat konvensional dengan perubahan dimensi & Rp 452.336.482,86 & 20 hari \\
Pelat half precast dengan perubahan dimensi & Rp 439.421.474,33 & 12 hari \\
Balok konvensional (existing) & Rp 408.732.541,21 & 14 hari \\
Balok konvensional dengan perubahan dimensi & Rp 382.305.688,16 & 14 hari \\
Balok precast dengan perubahan dimensi & Rp 367.866.138,24 & 13 hari \\
Kolom konvensional (existing) & Rp 438.858.133,02 & 16 hari \\
Kolom konvensional dengan perubahan dimensi & Rp 416.620.012,62 & 16 hari \\
Kolom precast dengan perubahan dimensi & Rp 416.318.257,00 & 14 hari \\
\hline
\end{tabular}

Dari tabel diatas dapat dilihat jika pekerjaan dengan metode precast memiliki biaya lebih murah dan waktu lebih singkat daripada menggunakan metode konvensional.

Setelah dilakukan perhitungan, dibuat kombinasi alternatif berdasarkan pengalaman dan kemudahan pelaksanaan di lapangan dan kemudahan pelaksanaan yang dapat dipilih yaitu:

1. Pelat, balok, dan kolom tipe konvensional dengan perubahan dimensi

2. Pelat, balok, dan kolom precast dengan perubahan dimensi

3. Kombinasi pelat precast dengan balok dan kolom konvensional dengan perubahan dimensi

Untuk memudahkan dalam menganalisis Value Engineering dalam memilih solusi terbaik, diusulkan kriteria-kriteria dari item pekerjaan yang dianalisis. Kriteria ini merupakan aspek penting dalam pelaksanaan pekerjaan pelat, balok, dan kolom. Berikut kriteria yang akan digunakan pada penelitian ini:

Kriteria I : Kekuatan Struktur

Kriteria II : Biaya Pelaksanaan

Kriteria III : Waktu Penyelesaian

Kriteria IV : Workability

Kriteria V : Estetika dan Penampilan 
Jurnal Matriks Teknik Sipil

DOI: https://dx.doi.org/10.20961/mateksi.v9i1.51241

ISSN: 2354-8630

E-ISSN: 2723-4223

Vol 9, No 1 (2021): Maret

\section{Tahap Analisis}

Setelah didapatkan alternatif dan kriteria yang diperbandingkan, maka dilanjutkan perhitungan AHP menggunakan bantuan Software Expert Choice.

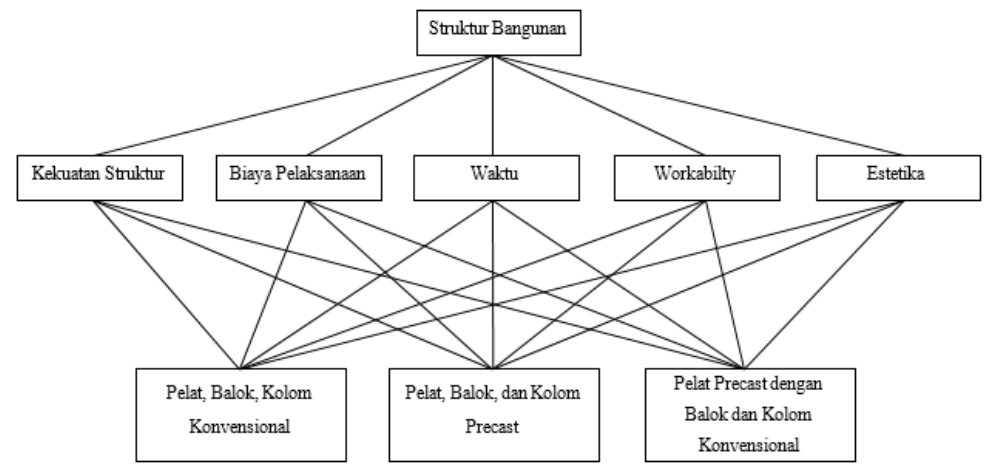

Gambar 2. Struktur hierarki penelitian

Dapat dilihat pada gambar diatas, level pertama merupakan tujuan/goals, level kedua merupakan kriteria yang perlu diperhatikan, dan level terakhir merupakan alternatif yang dapat dipilih.

Untuk kritera biaya pelaksanaan, kekuatan struktur, dan waktu penyelesaian didapat dari data kuantitatif. Sedangkan metode pelaksanaan dan estetika digunakan data kualitatif dari kuisioner yang telah dibagikan. Sebelum dilakukan analisis, perlu dilakukan perhitungan bobot normalisasi pada data kuantitatif, proses ini bertujuan untuk menemukan urutan prioritas dalam skala 1 .

Dari hasil pembobotan normalisasi dan hasil kuisioner dari responden, dilanjutkan input semua data ke Expert Choice untuk semua responden. Dalam menginput bobot masing-masing elemen perlu diperhatikan nilai inkonsistensinya.



Gambar 3. Input bobot elemen menggunakan Expert Choice

Dapat dilihat pada gambar, nilai inkonsistensinya sebesar 0,06 sehingga masih memenuhi syarat. Apabila memiliki nilai lebih dari 0,1 maka responden tersebut dieliminasi. Setelah selesai perhitungan pada satu responden, dilanjutkan untuk responden lainnya dengan cara yang sama. 
Jurnal Matriks Teknik Sipil

DOI: https://dx.doi.org/10.20961/mateksi.v9i1.51241

ISSN: 2354-8630

E-ISSN: 2723-4223

Vol 8, No 4 (2021): Maret

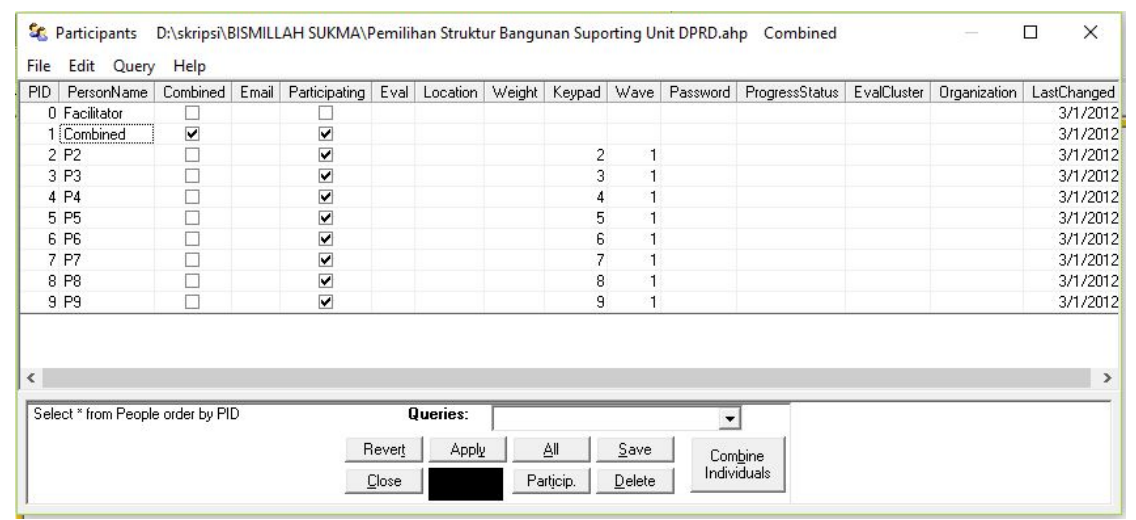

Gambar 4. Kombinasi responden dalam perhitungan

Setelah selesai input untuk semua responden maka dilakukan kombinasi responden untuk memperoleh hasil kumulatif seperti pada gambar diatas.

\section{Tahap Pengembangan}

Pada tahap ini didapatkan alternatif yang terpilih, kemudian diestimasi efisiensi yang terjadi dari desain asal dengan desain yang baru diusulkan.

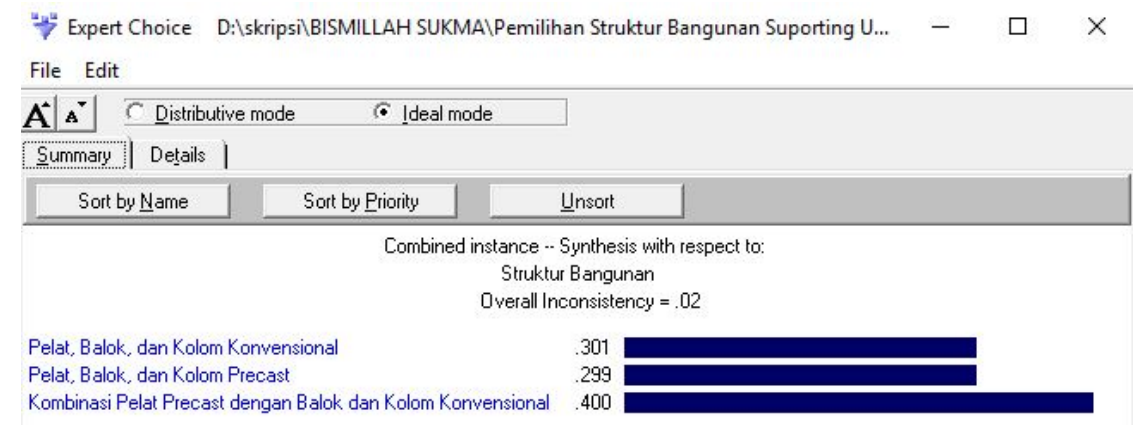

Gambar 5. Hasil perhitungan Expert Choice

Dari hasil perhitungan Expert Choice, alternatif struktur bangunan yang terpilih adalah pelat precast dengan balok dan kolom konvensional dengan bobot $40 \%$. Alternatif tersebut lebih unggul dibanding pelat, balok, dan kolom konvensional sebesar 30,1\%; pelat, balok, dan kolom precast sebesar 29,9\%. Dapat dilihat jika nilai inkonsistensi sebesar $2 \%$ sehingga masih memenuhi syarat.

Tabel 6 Perhitungan efisiensi pekerjaan

\begin{tabular}{lllll}
\hline No. & Item Pekerjaan & Cost & Worth & Efisiensi \\
\hline 1 & Pekerjaan Pelat & $R p ~ 622.465 .395,24$ & $R p ~ 439.421 .474,33$ & 1,439 \\
\hline 2 & Pekerjaan Balok & $R p ~ 408.732 .541,21$ & $R p ~ 382.305 .688,16$ & 1,069 \\
\hline 3 & Pekerjaan Kolom & $R p ~ 438.858 .133,02$ & $R p ~ 416.620 .012,62$ & 1,053 \\
\hline
\end{tabular}

Efisiensi pekerjaan dihitung dari perbandingan nilai cost dan worth. Nilai efisiensi menunjukkan besarnya penghematan yang terjadi. Pada perhitungan ini, diperoleh nilai efisiensi lebih dari 1 pada semua pekerjaan yang menunjukkan adanya penghematan biaya pada masing-masing pekerjaan.

\section{Tahap Rekomendasi}

Pada tahap ini berupa penyampaian hasil analisis kepada pihak pengambil keputusan. Dipaparkan dari rencana awal, alternatif yang ditawarkan, serta dasar pertimbangan. 
Pada rencana awal, digunakan pelat precast dengan balok dan kolom konvensional (existing) dengan biaya pekerjaan sebesar Rp 1.470.055.069,47. Berdasarkan perhitungan biaya, perhitungan durasi, dan analisis kuesioner yang dihitung menggunakan bantuan program Expert Choice, terpilih alternatif pelat preast dengan balok dan kolom konvensional (dengan perubahan dimensi). Alternatif ini dapat menghemat biaya pekerjaan sebesar 15,76\% dari rencana awal sebesar Rp 1.470.055.069,47 menjadi Rp 1.238.347.175,11. Pertimbangan yang mendasari terpilihnya alternatif tersebut adalah,

1. Kekuatan struktur

2. Penghematan biaya pelaksanaan

3. Waktu penyelesaian yang lebih singkat

4. Kemudahan dalam pengerjaan (workability)

5. Estetika atau penampilan

\section{SIMPULAN}

Berdasarkan analisis Value Engineering yang dilakukan pada proyek Supporting Unit DPRD Kota Salatiga dapat diambil kesimpulan sebagai berikut:

1. Dalam studi ini, item pekerjaan yang dipilih untuk dilakukan V alue Engineering adalah pekerjaan pelat, kolom, dan balok.

2. Alternatif yang terpilih tidak berbeda dengan tipe struktur awal yaitu pelat precast dengan kolom dan balok konvensional dengan dilakukan perubahan dimensi.

3. Dari analisa Value Engineering yang dilakukan, didapatkan penghematan / cost saving sebesar Rp 231.708.894,36 atau sebesar 2,55\% dari keseluruhan biaya proyek.

\section{REKOMENDASI}

Setelah melakukan analisis maka dapat disampaikan beberapa hal yang harus dilakukan dalam melakukan Value Engineering khususnya pada pembangunan gedung, diantaranya:

1. Penerapan Rekayasa Nilai tidak terbatas pada pekerjaan struktur, tetapi dapat pula dilakukan pada pekerjaan lainnya yang memiliki prosentase biaya besar, seperti pada pekerjaan arsitektur, mekanikal dan elektrikal.

2. Banyaknya alternatif yang ditawarkan membuat semakin variatif karena semakin banyak alternatif yang dapat dibandingkan dan dipilih.

3. Semakin banyak responden yang dilibatkan akan membuat pembobotan dan penilaian semakin bervariasi.

4. Untuk mendapatkan penghematan terbaik, sebaiknya dilakukan Rekayasa Nilai pada tahap desain.

\section{UCAPAN TERIMAKASIH}

Terima kasih penulis ucapkan kepada Ibu Dr. Fajar Sri Handayani, S.T., M.T. serta Bapak Muji Rifai, S.T., M.T. sebagai dosen pembimbing pertama dan kedua dalam penelitian ini. Terima kasih kepada kedua orang tua, adik, dan para sahabat yang telah memberi semangat hingga terselesaikannya tugas akhir ini.

\section{REFERENSI}

Anisa” Wahyu T., 2013, “Aplikasi Value Engineering dengan Metode Analytical Hirarchy Process (AHP) terhadap Struktur Pelat pada Proyek Pembangunan Hotel Aziza Solo", Universitas Sebelas Maret. Surakarta.

Badan Standarisasi Nasional, 2012, “SNI 2847:2019:Persyaratan Beton Struktural Untuk Bangunan Gedung”, Badan Standarisasi Nasional. Jakarta.

Badan Standarisasi Nasional, 2012, "SNI 7832:2012 : Tata Cara Perhitungan Harga Satuan Pekerjaan Beton Pracetak Untuk Konstruksi Bangunan Gedung”, Badan Standarisasi Nasional. Jakarta.

Badan Standarisasi Nasional, 2019, "Persyaratan Beton Struktural untuk Bangunan Gedung dan Penjelasan", SNI 2847:2019, Departemen Pekerjaan Umum, Yayasan Lembaga Penyelidikan Masalah Bangunan. Bandung.

Dell'Isola, A., 1974, "V alue Engineering in the Construction Industry", Construction Publishing Corp., Inc., New York.

Dipohusodo, I., 1999, "Struktur Beton Bertulang Berdasarkan SK SNI T-15-1991-03 Departemen Pekerjaan Umum”, Gramedia. Jakarta.

Diyar Rahma, 2018, "Analisis Value Engineering dengan Metode Zero-one pada Proyek Pembangunan Gedung Laboratorium Komputer Kampus 3 Universitas Ahmad Dahlan Yogyakarta”, Universitas Sebelas Maret, Surakarta.

Donomartono, 1999, “Aplikasi Value Engineering Guna Mengoptimalkan Biaya pada Tahap Perencanaan Konstruksi Gedung dengan Struktur Balok Beton”. 
Jurnal Matriks Teknik Sipil

ISSN: 2354-8630

E-ISSN: $2723-4223$

Vol 8, No 4 (2021): Maret

Gabriel Kusumo H., 2018, “Analisis Metode Value Engineering Untuk Efisiensi Biaya (Studi Kasus : Proyek Apartemen Yukata Suites Alam Sutera Tangerang", Universitas Sebelas Maret. Surakarta.

Hutabarat, J., 1995, “Diktat Rekayasa Nilai (Value Engineering)", Institut Teknologi Nasional. Malang.

Irfansyah, Puput., 2015, "Sistem Pendukung Keputusan Penentuan Lokasi Pemasangan Iklan Ajang Promosi Bimbel Menggunakan Metode Analytical Hierarchy Process". JABE Vol 2, No 1.

Miles, L. D., 1947, "The Cost Problem and The Value Engineering Approach".

Nasrul, Rozanya, 2017, "Penerapan Metode Value Engineering Pada Proyek Pembangunan Asrama Putera Yayasan Tapuz Kota Pariaman". ITP Open Conference System.

Nawy, E. G., 1998, “Beton Bertulang: Suatu Pendekatan Dasar”, PT. Rafika Aditama. Bandung

Priyanto, Herry, 2010, "Pengoptimalan Penerapan Value Engineering pada Tahap Desain Bangunan Gedung di Indonesia”, 'Tesis Fakultas Teknik. Universitas Indonesia.

PU., 1991, "Permen PU No. 222/KPTS/CK/1991 : Pedoman Operasional Penyelenggaraan Gedung Negara", PU. Jakarta.

PU., 2007, "Permen PU No.45/PRT/M/2007 : Pedoman Teknis Pembangunan Bangunan Gedung Negara”. PU. Jakarta.

Ramiadji, Djoko., 1996, "Penerapan Efisiensi Nilai Teknis (Value Engineering) Sebagai Suatu Usaha Efisiensi Dana Pembangunan”, Majalah Jalan dan Transportasi 304. Jakarta

Saaty, T. L., 1991, "Decision Making for Leaders, The Abalytic Hierarchy Process for Decisions In A Complex Word".

Sudarmoko., 1996, "Perencanaan dan Analisis Kolom Beton Bertulang”, Biro Penerbit. Yogyakarta. 